\title{
Muscle afferent potential ('A-wave') in the surface electromyogram of a phasic stretch reflex in normal humans
}

\author{
Alex. M. Clarke, PAtricia T. Michie, AND LeONARD C. T. Glue \\ From the School of Behavioural Sciences, Macquarie University, \\ North Ryde, New South Wales, Australia
}

SUMMARY The experiments reported in this paper tested the hypothesis that the afferent potential elicited by a tendon tap in an isometrically recorded phasic stretch reflex can be detected in the surface EMG of normal humans when appropriate techniques are used. These techniques involved (1) training the subjects to relax mentally and physically so that the EMG was silent before and immediately after the diphasic MAP which reflects a highly synchronous discharge of afferent impulses from low threshold muscle stretch receptors after a tendon tap, and (2) using a data retrieval computer to summate stimulus-locked potentials in the EMG over a series of 16 samples using taps of uniform peak force and duration on the Achilles tendon to elicit the tendon jerk in the calf muscles. A discrete, diphasic potential ('A-wave') was recorded from EMG electrodes placed on the surface of the skin over the medial gastrocnemius muscle. The 'A-wave' afferent potential had the opposite polarity to the corresponding efferent MAP. Under control conditions of relaxation the 'A-wave' had a latency after the onset of the tap of $2 \mathrm{msec}$, the peak to peak amplitude was of the order of $5 \mu \mathrm{V}$ and the duration was in the range of 6 to $10 \mathrm{msec}$. Further experiments were conducted to show that the 'A-wave' (1) was not an artefact of the instrumentation used, (2) had a threshold at low intensities of stimulation, and (3) could be reliably augmented by using a Jendrassik manoeuvre compared with the potential observed during control (relaxation) conditions. The results support the conclusion that the 'A-wave' emanates from the pool of muscle spindles which discharges impulses along group Ia nerve fibres in response to the phasic stretch stimulus because the primary ending of the spindles is known to initiate the stretch reflex and the spindles can be sensitized by fusimotor impulses so that their threshold is lowered as a result of a Jendrassik manoeuvre. The finding has important implications for the investigation of the fusimotor system in intact man.

When a tendon is tapped by a hammer to elicit a tendon jerk, the muscle action potentials (MAP) observed in the surface electromyogram (EMG) are the end result of an initial afferent volley from the muscle receptors which responded to the stretch stimulus. The experiments reported in this paper were designed to test the hypothesis that the afferent potential elicited by a tendon tap can be detected in the surface EMG of humans when appropriate techniques are used.

The afferent discharges from muscle have been recorded in the dorsal roots and directly from the muscle spindles of infra-human preparations (Lloyd, 1943; Cooper, 1962; Matthews, 1964). Although attempts have been made to record neurograms in response to tendon taps using needle electrodes inserted percutaneously near nerve fibres (Gassel and Diamontopoulos, 1966; Hagbarth and Vallbo, 1968), no reports have appeared of research specifically aimed at detecting with surface electrodes the afferent volley from muscle receptors in response to a tendon tap. In research on the nature of evoked potentials to auditory stimuli in man Bickford, Jacobson, and Cody (1964) have reported the extraneous finding of invariant early waves of short latency and probable myogenic origin that were detected from surface electrodes placed between the inion and the left ear. These waves were not observable in the raw electromyogram but were detected after averaging 150 signals with a computer of average transients. During an investigation of muscle potentials in reaction 
time Luschei, Saslow, and Glickstein (1967) also reported an unexpected finding of short-latency potentials. These were observed with EMG surface electrodes in all four monkeys involved in the experiment after summing the signals over a large number of trials with a computer. The observations were confirmed on a human subject with intramuscular leads. The authors discussed the possibility that the early bioelectrical activity was related to the response of muscle spindles (Bickford, et al., 1964; Luschei et al., 1967).

Sears (1959) has shown that it is possible to record from skin electrodes the afferent impulses in sensory nerve evoked by synchronous excitation of mechanoreceptors in the human finger by tapping the base of the finger nail. Recently Hagbarth and Vallbo (1968) in work with normal humans have used tungsten electrodes inserted percutaneously into the muscular portion of the tibial nerve branch to calf muscles to record multi-fibre neurograms. Simultaneously EMG recordings from surface electrodes were made in response to taps on the Achilles tendon. 'Each tap caused a marked afferent neural discharge that reached a maximum amplitude within 5 to $10 \mathrm{msec}$ ' and, although Hagbarth and Vallbo did not explicitly comment on it, a discrete discharge of about $8 \mu \mathrm{V}$ (peak to peak) can be observed after the stimulus artefact in the surface EMG with a latency of $2.5 \mathrm{msec}$ after the onset of the tap (their Fig. 6, p. 684). The differences in latency reflect the closer proximity of the EMG electrodes to the sensory receptors which were situated more distal to neurogram electrodes.

One of the conditions thought to be necessary for recording afferent neural discharge in humans is a synchronous discharge to the mechanical stimulus (Sears, 1959; Gassel and Diamantopoulos, 1966; Hagbarth and Vallbo, 1968). In the case of tendon jerks the taps used by these researchers were particularly brisk with the aim of achieving synchronous afferent discharges of short duration and relatively high amplitude.

The rationale for the present experiments rests on the assumptions that:

1. a subject can be trained to relax by Jacobson's technique (1924) so that the EMG is silent before and immediately after the discrete, diphasic MAP in which case this highly synchronous discharge of motor units is the result of a similar synchrony in the afferent volley; and

2. under these conditions it would be possible to detect the tiny afferent potential from surface electrodes by summing a number of responses to⿱ a tendon tap with a data retrieval compute using a signal 'averaging' technique. Potential that are time-locked to the onset of the tendor tap will sum to progressively higher levels witho successive trials, whereas those random, back ?़ ground-noise, signals not caused by the stimulus tend to cancel.

METHODS

Five normal subjects (two males and three females age range 19 to 45 years) with brisk reflexes were studied. They were tested in a blacked-out, sound $\cong$ attenuated and air-conditioned room so that adess quate control was achieved over environmenta $\vec{b}$ variables known to affect the parameters of the stretch reflex (Clarke, 1965). The subjects had beerw well trained in mental and physical relaxation (Jacobson, 1924) and were able to maintain a con sistent level of muscle tonus over the period of thes experimental session. The subjects lay supine on of rubber mattress with earmuffs over the ears (Ear guard, Type EML 45).

A solenoid driven hammer was used to tap the Achilles tendon; the parameters of the voltage pulse operating the solenoid could be altered. changing the voltage, the peak force of the tap confe. be varied in the range of 0.15 to $1.95 \mathrm{~kg}$. By alter the pulse width, the duration of the tap could varied in the range 15 to $35 \mathrm{msec}$. Forces of the order of $1.5 \mathrm{~kg}$ were generally used with the peako being reached within 7 or $8 \mathrm{msec}$. Foil strain gauges mounted on the head of the hammer permitted the recording of the force-time relationship of the tap during each mechanical stimulation.

The subject's left foot was strapped to a hinged $\vec{b}$ fibre-glass footplate behind which was mounted $\mathrm{a}^{\mathrm{P}}$ Statham bi-directional transducer (Type UC2) and load cell adaptor (Type UL/20). This enabled the resting tension of the gastrocnemius muscle to be observed during the experimental period to see that no changes occurred in the base-level of the myo gram before each isometric reflex contraction. Move ment of the knee-joint was prevented by strapping the leg below the knee to the base of the bed.

MAPs were recorded through Beckman bio오 potential skin electrodes placed $1 \frac{1}{2}$ in. apart over thes belly of the medial gastrocnemius muscle with ar? earth electrode on the thigh. The skin resistance was less than $1,000 \Omega$. MAPs were amplified through $a^{\mathrm{N}}$ balanced amplifier (response $3 \mathrm{db}$ down at $15 \mathrm{~Hz}$ to $10 \mathrm{kHz}$; gain of $80 \mathrm{db}$ ).

The percussion wave propagated through the gastrocnemius muscle of the leg by the tap on the tendon was recorded by means of a crystal cartridge् secured by adhesive tape to the skin between the EMG electrodes. In some experimental sessions theo 
EMG and percussion wave were recorded, in addition, from the anterior tibialis muscle. Tendon taps were given at least 15 seconds apart to permit the subject to relax fully between presentations of the stimuli.

The individual responses were displayed on the screen of a Tektronix, Type 549 , cathode ray storage oscilloscope (CRO). Sequences of responses were summated in the memory store of a Nuclear Chicago Model $\mathbf{1 7 0 0}$ data retrieval computer (DRC) for the various control and experimental treatments. A sampling interval of $62 \mathrm{msec}$ was used to enable the entire period between the onset of the voltage pulse used to trigger the solenoid-hammer and the first deflection from the base-line of the MAP to be scanned by the DRC. Sets of 16 successive samples of these data were computed for ease of calibration of the resulting signals. CRO and DRC traces were photographed with a Polaroid camera.

\section{RESULTS}

The MAP in response to the brief mechanical stretch of the muscle was highly synchronous without any evidence of repetitive activity (Fig. 1). With each subject an early diphasic potential (here after called the 'A-wave') was detected in the EMG trace on the DRC screen after 16 sweeps (Fig. 2). Under control conditions of relaxation, the A-wave had a latency after the onset of the tap of the order of $2 \mathrm{msec}$. The peak to peak amplitude was of the order of $5 \mu \mathrm{V}$ and the total duration of the positive and negative components of the diphasic potential was in the range of 6 to $10 \mathrm{msec}$. The ratio of the computed A-wave to the mean of the 16 MAPs ranged from 1 in 80 to 1 in 350 for the five subjects during control conditions of relaxation.

Subsequent research was aimed at demonstrating the validity of the potential as a bioelectrical signal by showing that it (a) was not an artefact of the instrumentation used, (b) exhibited characteristics of physiological phenomena such as displaying a threshold at lower limits of stimulation, the property of facilitation and a shift in latency under augmented conditions, and (c) was related temporally with the afferent potential recorded from surface electrodes placed on the fossa over the medial popliteal nerve.

The results of these experiments are summarized below:

1. The A-wave was shown not to be correlated with the onset or offset of the voltage pulse which activated the solenoid-controlled hammer head (Fig. 2).

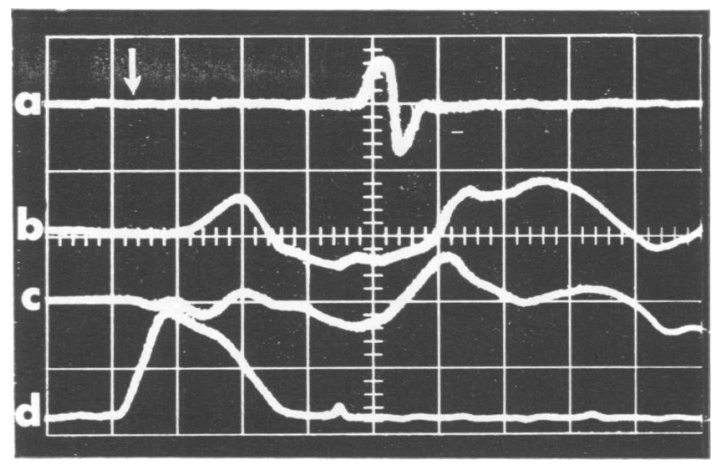

FIG. 1. Oscilloscope traces of the electromyogram, percussion waves, and force of tap on the tendon for one of the sweeps from the set of 16 sweeps summated in the DRC and shown in Fig. 2. Subject K.B.

Channel a. The EMG recorded from the medial gastrocnemius muscle. Note the discrete, diphasic $M A P$ which indicates the synchronous firing of motor units. The arrow shows the position on the EMG record, in relation to the onset of the tap, where the A-wave appears in the signal averaging computer trace (see Fig. 2). Vertical scale: $200 \mu$ V/division.

Channel $\mathrm{b}$. The percussion wave recorded from $a$ crystal cartridge placed in position between the EMG electrodes over the belly of the medial gastrocnemius muscle. Vertical scale: 0.05 V/division.

Channel c. The percussion wave recorded from a crystal cartridge placed in position between the EMG electrodes over the belly of the anterior tibialis muscle.

Channel d. The force of the tap on the Achilles tendon. Vertical scale: $1 \mathrm{~kg} /$ division.

Horizontal scale for all channels: $10 \mathrm{msec} /$ division.

2. The A-wave was shown not to be an artefact of the percussion wave which was propagated through the muscle by the mechanical tap for the following reasons.

i. When the force of the tap on the tendon was held constant over trials within an experimental session the A-wave could be augmented by a Jendrassik manoeuvre (JM) in a set of experimental trials compared with the A-wave in a corresponding set of control trials during which the subject relaxed. The percussion wave, however, did not change in wave form or amplitude during experimental and control trials.

ii. When the A-wave was detected in the medial gastrocnemius it was not evident in simultaneous EMG recordings in the anterior tibialis muscle (Fig. 2). The absence of an EMG response in the anterior tibialis muscle was predicted because its tendon is lateral to the 


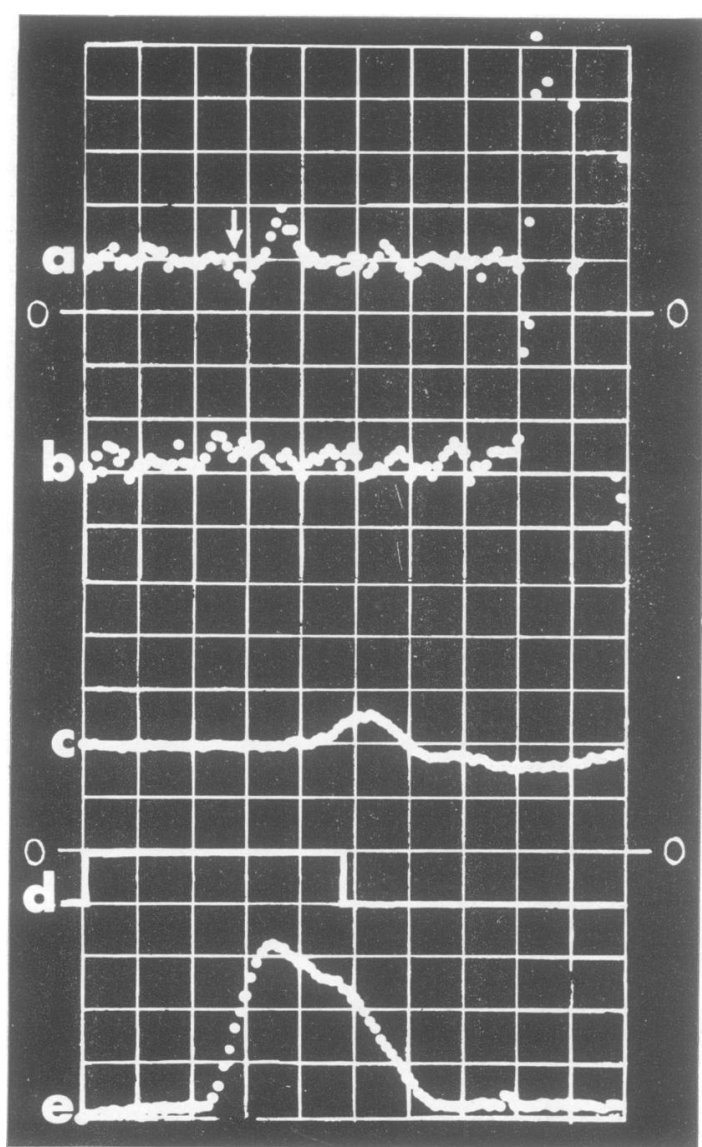

anterior border of the tibia and runs across the front of the ankle to the medial side of the foot. The muscle is not stretched by a tap of the Achilles tendon. If the A-wave had been an artefact of percussion, then a potential would have appeared in the EMG of the anterior tibialis muscle because an appreciable percussion wave was recorded from it (Fig. 1).

iii. There was no relationship evident between the shape and amplitude of the percussion wave and the shape and amplitude of the EMG over the analysis interval used of $62 \mathrm{msec}$ (Fig. 1).

iv. When the peak force of the tap on the tendon was so small $(150 \mathrm{~g})$ that no MAPs were detectable in the EMG but a significant percusion wave was recorded, no A-wave was detected in EMG display after 16 sweeps were summated in the DRC at a gain of $1 \cdot 1 \mu \mathrm{V} / \mathrm{cm}$.

$v$. There were some experimental sessions in which the usual peak force of tap (about $1.5 \mathrm{~kg}$ ) was used to elicit the tendon jerks but no A-wave was observed after 16 sweeps were summated in
FIG. 2. Traces on the screen of the Data Retrievals Computer of the reflex responses obtained after $1 \%$ sweeps of the various responses. Subject K.B.

Channel a. The EMG from medial gastrocnemiuse muscle (above the top 0-O line) showing the afferent? potential which begins (as indicated by the arrow) 2 msec after the onset of the tap on the Achilles. tendon. The first deflection of the MAP with a latency of $35.5 \mathrm{msec}$ can be seen at the right hand end of the trace. The mean MAP for this set of 16 sweeps was $350 \mu \mathrm{V}$. Vertical scale: $1.53 \mu \mathrm{V} /$ division.

Channel b. The EMG from anterior tibialis. muscle showing a random noise pattern without any detectable signal following the tap. Vertical scale. is $1.53 \mu \mathrm{V} /$ division.

Channel c. The percussion wave recorded from $a-$ crystal cartridge sited on the skin between the elec- $\vec{\omega}$ trodes over the medial gastrocnemius muscle. Vertica? scale: $15 \cdot 30 \mathrm{mV} /$ division.

Channel d. The voltage pulse used to activate the solenoid hammer. The A-wave is not associated with the onset or offset of the pulse. Vertical scale: iv 25 V/division.

Channel e. The force of the tap on the Achilleso tendon delivered by the solenoid hammer. Verticalscale: $0.75 \mathrm{~kg} /$ division.

Horizontal scale for all channels: $6.20 \mathrm{~ms}$ \& division.

the DRC. The absence of a detectable A-wave in these sessions probably was the result of asyn-응 chrony in the afferent discharges as indicated by $\overrightarrow{0}$ the tri-phasic MAPs that were recorded.

3. The A-wave was observed to obey two established physiological principles-the property of facilitation and a threshold for low intensities of stimulation. These principles were demonstrated as follows.

i. The A-wave consistently displayed a greater amplitude and shorter latency (as did the MAPs) under JM conditions compared with controlo (relaxation) trials and could be reliably changed according to the sequence of treatment (Table음 1). A counterbalanced design was used to control for the possible effects of the sequence of presentation. There was no change in other relevant variables during the presentation of $\omega$ these control and JM treatments-that is, consistency was observed in (a) the base-level of the myogram as an index of the resting tension of the gastrocnemius muscle, (b) the peak force and 
TABLE 1

COMPARISONS BETWEEN PEAK TO PEAK AMPLITUDE AND LATENCY OF A-WAVE OBSERVED FROM MEANS OF SETS OF 16 SWEEPS IN DATA RETRIEVAL COMPUTER FOR CONTROL CONDITIONS OF RELAXATION AND EXPERIMENTAL CONDITIONS USING A JENDRASSIK MANOEUVRE (JM) WITH PF.AK FORCE OF TAP ON TENDON HELD CONSTANT WITHIN EXPERIMENTAL SESSIONS

\begin{tabular}{|c|c|c|c|c|c|}
\hline \multirow[t]{2}{*}{ Subject } & \multirow[t]{2}{*}{ A-wate } & \multicolumn{4}{|c|}{$\begin{array}{c}\text { Sequence in which conditions } \\
\text { were presented }\end{array}$} \\
\hline & & Control & $J M$ & Control & $J M$ \\
\hline \multirow[t]{2}{*}{ J.O. } & Amplitude $(\mu \mathrm{V})$ & $6 \cdot 1$ & $7 \cdot 7$ & 6.9 & 一 \\
\hline & Latency (msec) & $2 \cdot 0$ & $1 \cdot 0$ & $2 \cdot 0$ & 一 \\
\hline \multirow[t]{2}{*}{ J.L. } & Amplitude $(\mu \mathrm{V})$ & $3 \cdot 7$ & $9 \cdot 2$ & $2 \cdot 7$ & - \\
\hline & Latency (msec) & $2 \cdot 0$ & $1 \cdot 3$ & $1 \cdot 8$ & 一 \\
\hline \multirow[t]{2}{*}{ S.A. } & Amplitude $(\mu \mathrm{V})$ & - & $4 \cdot 6$ & $3 \cdot 8$ & $4 \cdot 8$ \\
\hline & Latency (msec) & 一 & $1 \cdot 6$ & $2 \cdot 0$ & 1.6 \\
\hline \multirow[t]{2}{*}{ S.A. } & Amplitude $(\mu \mathrm{V})$ & - & $4 \cdot 9$ & $3 \cdot 8$ & $5 \cdot 7$ \\
\hline & Latency (msec) & - & $1 \cdot 5$ & $2 \cdot 1$ & $1 \cdot 5$ \\
\hline \multirow[t]{2}{*}{ J.S. } & Amplitude ( $2 \mathrm{~V})$ & $1 \cdot 5$ & 1.9 & $1 \cdot 5$ & - \\
\hline & Latency (msec) & $2 \cdot 5$ & $2 \cdot 0$ & $2 \cdot 5$ & - \\
\hline
\end{tabular}

duration of the taps on the tendon as an indication of the uniformity of the mechanical stimuli used to elicit the tendon jerks, and (c) the shape of the percussion wave propagated through the muscle by the taps as an index of the consistency of muscle tonus.

The ratio of the computed A-wave and the average MAP for the sets of 16 trials altered from the order of $1 / 60$ during control (relaxation) conditions to ratios in the range $1 / 150$ to 1/940 during JM conditions.

ii. As progressively smaller peak forces of tap on the tendon were given there was a progressive reduction in the amplitude of both the MAP and the A-wave until the stimulus was below threshold. At this level neither the A-wave nor the MAP were apparent in the random background activity of the EMG which was $0.95 \mu \mathrm{V}$ peak to peak (Table 2).

4. Simultaneous surface recordings from electrodes over the medial gastrocnemius muscle and over the popliteal fossa showed that a deflection occurred in the neurogram $3.0 \mathrm{msec}$ after the A-wave began in the electromyogram. The distance between the two sets of recording electrodes was $15 \mathrm{~cm}$. The calculated conduction velocity of $50 \mathrm{~m} / \mathrm{sec}$ is consistent with the velocity with which impulses are known to travel along group Ia afferent nerve fibres (Hunt, 1952).

5. Since the A-wave and the MAP were recorded from the same pair of skin electrodes over the medial gastrocnemius muscle, one would expect an afferent potential to have the reverse
TABLE 2

MEANS OF DATA OBTAINED IN DATA RETRIEVAL COMPUTER FOR SETS OF 16 SWEEPS TO SHOW A THRESHOLD AT LOW INTENSITY STIMULATION. SUBJECT J.S.

\begin{tabular}{lcc}
\hline $\begin{array}{l}\text { Mean peak force } \\
\text { of tap on } \\
\text { Achilles tendon } \\
(\mathrm{kg})\end{array}$ & $\begin{array}{c}\text { Reflex response of medial gastrocnemius muscle } \\
\text { Mean peak to peak }\end{array}$ & $\begin{array}{c}\text { Mean peak to peak } \\
\text { amplitude of } M A P \\
(\mu \mathrm{V})\end{array}$ \\
\cline { 2 - 3 } & $(\mu \mathrm{V})$ & 495 \\
2.25 & $5 \cdot 4$ & 125 \\
1.31 & $2 \cdot 3$ & Not detectable at \\
0.75 & Not detectable at \\
& gain of $1 \cdot 1 \mu \mathrm{V} / \mathrm{cm}$ & \\
& Noise level $0.95 \mu \mathrm{V}$ & \\
\hline
\end{tabular}

polarity to an efferent potential detected by these electrodes. The A-wave had an initial negative deflection (Fig. 1), whereas the efferent muscle action potential had an initial positive deflection in the EMG (Figs 1 and 2). When the neurogram was recorded in the popliteal fossa simultaneously with the EMG, the polarity of the A-wave and the neural action potential were the same. These observations support the view that the A-wave is an action potential of afferent nerve fibres.

\section{DISCUSSION}

These results demonstrate that the early potential or A-wave in the EMG is not a percussion or electronic artefact but is a bioelectrical signal of afferent origin. It is known that the low threshold primary ending of muscle spindles responds well to the dynamic component of stretch and impulses from it initiate the myotatic reflex (Hunt and Perl, 1960; Cooper, 1962; Matthews, 1964). Further, signals recorded in large Ia afferent fibres tend to be more easily detected than signals in group II and tendon organ afferent fibres in human studies (Hagbarth and Vallbo, 1968). Therefore, there is a strong evidence from these experiments for the inference that the A-wave is the action potential from the pool of spindles which discharges a relatively synchronous volley of impulses along group Ia nerve fibres in response to the phasic stretch of the muscle.

The amplitude and latency of the A-wave are not inconsistent with expectations about these parameters of a synchronous afferent potential. Potentials of approximately $7 \mu \mathrm{V}$ amplitude with a latency of $2.5 \mathrm{msec}$ can be seen in the surface EMG from calf muscles after the artefact of the 
mechanical stimulus used to elicit the tendon jerk in Fig. 6 of the paper by Hagbarth and Vallbo (1968).

The duration of the A-wave is longer than anticipated, being in the range 6 to $10 \mathrm{msec}$. However, the early potentials of probable myogenic origin which Bickford et al. (1964) detected in their study of potentials evoked by auditory stimuli have a duration of this order. In discussing their findings on the differences between mechanically and electrically elicited monosynaptic reflexes in man, Gassel and Diamantopoulos (1966) state that there is 'a basic difference in the character of the afferent volley subserving the two reflexes; and the most apparent explanation is that the proprioceptive volley on tendon tap is dispersed, whereas that on H reflex is summated'. Sears (1959) also has pointed out that the action potential in response to brief mechanical stimulation of the sensory receptors in human fingernails is of longer duration than the antidromic volley elicited by electrical stimulation of the median nerve. It would appear that the findings from the present experiments about the duration of the A-wave lend support to these points of view.

The small but highly reliable augmentation of the A-wave as a result of Jendrassik manoeuvres can be expected on the basis of fusimotor sensitization of the intrafusal fibres of the muscle spindles (Kuffler, Hunt, and Quilliam, 1951). Under these conditions, a larger population of muscle spindles would be induced to discharge to the uniform mechanical stretch stimulus and the threshold of these receptors would be lowered by fusimotor impulses discharging the end plates on the contractile, polar ends of the spindle intrafusal fibres. Thus the afferent potential recorded at the surface of the skin should increase in amplitude and decrease in latency during JM conditions compared with control (relaxation) trials but in view of the size of the signals involved, only relatively small changes could be expected. The ratio of the computed A-wave to the mean MAP was always smaller under JM conditions than under control conditions. For example, with one subject (L.N.) the ratios were $1 / 90$ (control) and 1/150 (JM). The greater augmentation in the MAP compared with that in the A-wave is consistent with the observation that the sensitization of the spindles is not the sole facilitatory mechanism for the phasic stretch reflex; direct potentiation of alpha spinal cells by descending influences also seems to play some role (Clarke, 1967). Hagbarth anc Vallbo (1968) have commented that the ampli tude of the afferent responses observed in thein experiments was only slightly influenced b Jendrassik manoeuvres and they reported that in other work, they have detected neural dis charges in the tibial nerve which could be driven presumably through the fusimotor system, b painful electrical stimuli applied to the ulna: nerve. The authors concluded that impulses in? muscle spindle afferent fibres may contribute to these types of neural responses.

The technique reported in this paper for the detection at the surface of the skin of an afferen? discharge emanating from muscle spindles has important implications in two ways: first, in itș possible application in clinical neurophysiology as an index of the integrity of the fusimotor system, and second, in the possibility of extend ing the work of Buchwald and Eldred (1961) on classically conditioned responses in the gammar efferent pathways from cat to man.

We thank Professor A. K. McIntyre, Dr. R. F. $\overrightarrow{0}$ Mark, and Dr. J. Veale (Monash University) Associate Professor J. W. Lance, Dr. K. Lethlean and Dr. D. Burke (University of New South Waleg) and Dr. P. B. C. Matthews (Oxford University) discussions, Mr. D. Izard of Searle Nucleonics ret loaning the Nuclear Chicago Data Retrieval Computer Model 7100 for these experiments, and our subjects for giving their time for this research.

\section{REFERENCES}

Bickford, R. G., Jacobson, J. L., and Cody, D. T. R. (1964) Nature of average evoked potentials to sound and otherō stimuli in man. Annals of the New York Academy of Sciences, 112, 204-223.

Buchwald, J. S., and Eldred, E. (1961). Conditioned responses in the gamma efferent system. Journal of Nervous and Mental Disease, 132, 146-152.

Clarke, A. M. (1965). Relationship between the electromyo gram and the force of the isometric reflex response of normal human subjects. Nature, 208, 551-552.

Clarke, A. M. (1967). Effect of the Jendrassik manoeuvre on: a phasic stretch reflex in normal human subjects duringo experimental control over supraspinal influences. Journaß of Neurology, Neurosurgery, and Psychiatry, 30, 34-42.

Cooper, S. (1962). The behaviour of spindle receptors during muscle stretch. In Symposium on Muscle Receptors. Pro-D ceedings of a meeting held in 1961 at the University of Hong Kong, pp. 121-124. Edited by D. Barker. Hong Kong University Press: Hong Kong.

Gassel, M. M., and Diamantopoulos, E. (1966). Mechanically and electrically elicited monosynaptic reflexes in man.O Journal of Applied Physiology, 21, 1053-1058.

Hagbarth, K. E., and Vallbo, A. B. (1968). Discharge characteristics of human muscle afferents during muscle stretch< and contraction. Experimental Neurology, 22, 674-694.

Hunt, C. C. (1952). Peripheral origins of nervous activity. Cold Spring Harbor Symposium on Quantitative Biology,? 17, 113-123. 
Hunt, C. C., and Perl, E. R. (1960). Spinal reflex mechanisms concerned with skeletal muscle. Physiological Reviews, 40, 538-579.

Jacobson, E. (1924). The technic of progressive relaxation. Journal of Nervous and Mental Disease, 60, 568-578.

Kuffler, S. W., Hunt, C. C., and Quilliam, J. P. (1951). Function of medullated small-nerve fibres in mammalian ventral roots: efferent muscle spindle innervation. Journal of Neurophysiology, 14, 29-54.

Lloyd, D. P. C. (1943). Conduction and synaptic trans- mission of the reflex response to stretch in spinal cats. Journal of Neurophysiology, 6, 317-326.

Luschei, E., Saslow, C., and Glickstein, M. (1967). Muscle potentials in reaction time. Experimental Neurology, 18, $429-442$.

Matthews, P. B. C. (1964). Muscle spindles and their motor control. Physiological Reviews, 44, 219-288.

Sears, T. A. (1959). Action potentials evoked in digital nerves by stimulation of mechanoreceptors in the human finger. Journal of Physiology, 148, 30-31P. 